\title{
Review of 'Cultures and Disasters: Understanding Cultural Framings in Disaster Risk Reduction (2015)' edited by Fred Krüger, Greg Bankoff, Terry Cannon, Benedikt Orlowski, and E. Lisa F. Schipper
}

\author{
Olivia Wilkinson(1)
}

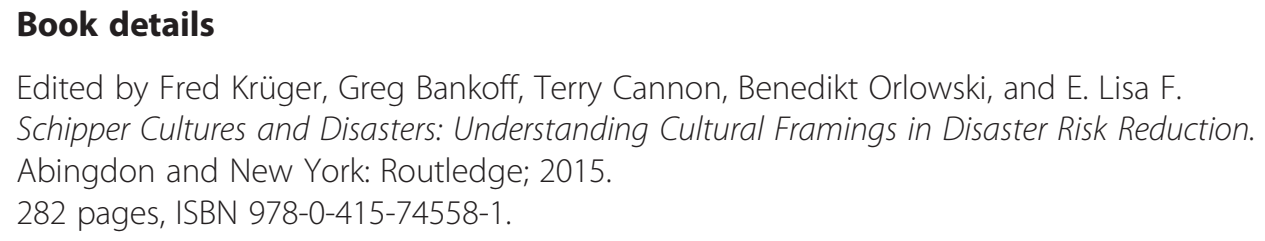

Emanating from two conferences held on culture and disasters in Germany in 2011 and 2013, this edited collection draws on the interdisciplinary expertise of a wide range of authors to examine the ways culture interacts with disasters, focusing particularly on disaster risk reduction (DRR). With an increased awareness of cultural opportunities and challenges in disaster as evidenced by the focus on culture and risk in the 2014 World Disasters Report (also edited by Cannon and Schipper) and the emphasis on the social, cultural, and environmental assets of people (as well as their economic and physical assets) in the Sendai Framework for DRR, this collection now reinforces the critical importance of research into culture and disaster for the improvement of future DRR measures by bringing together differing debates in one book.

The book is divided into three parts. Chapters in the first part focus on the more conceptual debates on the relationship between disaster and culture. This includes chapters on the dangers of dominant security discourses subsuming more nuanced, culturally specific debates in DRR from Hewitt, the impact of neoliberal culture on disaster risk from Oliver-Smith, an overview of architectural adaptations to earthquakes around the world from Bankoff, the opportunities and challenges of learning from

Correspondence: wilkino@tcd.ie

University of Dublin Trinity College, Dublin, Co Dublin, Ireland historical disasters from Schenk, and finally, a methodical explanation of the ways in which cultural influences strengthen or weaken people's vulnerability by Cannon-a chapter to be recommended as a wide-ranging overview of many of the issues involved in culture and disasters for those with a knowledge of DRR but wanting a more specific insight into cultural influences.

The second part of the book turns to examine the linkages between culture and vulnerability. Lewis begins the section with a chapter on corruption in construction, which provides a case of how culture can enhance vulnerability. Geiselhart et al. then approach culture from the level of the individual, examining how individuals' cultures influence their position in HIV/AIDS interventions in Botswana. Schipper follows with a broad examination of the ways in which religion can be included in DRR, and Crabtree finishes the section with a case of the deep, culturally ingrained responses of people surrounding the River Kosi when it flooded in 2008. This chapter particularly stands out as Crabtree engagingly integrates culture as one element of a comprehensive understanding of the disaster. In so doing, he provides a useful model of how researchers can write to incorporate culture into the whole picture of disaster without idealising or essentialising it. 
Part 3 provides further evidence of culture as it relates to disaster risk. The six chapters in this section range from an examination of celebrity culture in disaster from Alexander, an exposé of the instrumentalisation of local knowledge for DRR by decision-makers in Bangladesh from Cook, an outline of the difficulties of culture and risk in small island developing states (SIDS) with examples from Haiti, Comoros, and Timor-Leste from Kelman et al., an examination of the complexity of gender identities in cultural responses to disaster from Gaillard et al., an example of a DRR intervention that integrated religious teaching into its practice to build a culture of local preparedness and resilience in Padang, Indonesia, from Birkmann et al., and, to finish the edition, a reflection on ways to increase participation for improved resilience using the case of the Tao people in Taiwan from Voss and Funk.

Heralded by Ian Davis in one review as the 'long-awaited, definitive book' on culture and disaster, the editors of this edition in the Routledge Study series in Hazards, Disaster Risk, and Climate Change had much ground to cover. Such an edition had two main challenges. Firstly, it needed to show that the long-neglected area of culture had finally found its footing in the plethora of discussions on disaster and risk. Secondly, that the amorphous subject of 'culture' could be corralled into a coherent and meaningful space in chapters from a wide variety of authors. The book displays significant achievements on both accounts. Without forcing a definition, the editors allow individual authors to draw on their own understandings of cultures in disasters to shape their arguments. The edition demonstrates the utility of a pragmatic approach that allows the fluidity of culture to remain while keeping chapters on topic and relevant to each other. The concept of culture can still be a centralising force for such an edition without a heavy-handed approach to pre-defining and enforcing a meaning.

A pragmatic and flexible approach is also advocated by most authors in the book towards the inclusion of culture in disaster risk reduction as well. A theme running through most chapters is that there is a dominant 'western' (Cannon; Voss and Funk) or 'modern' (Hewitt; Geiselhart et al.) thought process in disaster management that is often unforgiving or incapable of capturing cultural processes essential to people's resilience. The editors call it the culture 'gap' in their introduction (p7). The question that is oft repeated is how to bridge such a divide. The critique of the dominant, elite, technologically focused status quo in disaster management is clearly made throughout. The way in which more locally centred, culturally specific knowledge and practice can work within the international humanitarian system is more contested. This pinpoints the very problem: that we try to force culture into a system that is ill equipped to include these specificities in its workings. In terms of solutions to the problem, 'genuine participation' with diversified identities in affected populations is one call from this collection (Gaillard et al.), while Voss and Funk recommend a transdisciplinary and integrative approach to vulnerability and resilience to ensure that marginalised voices and needs are heard in research and practice.

While many calls are made from the chapters' authors for increased awareness and inclusion of cultural perspectives in DRR, the chapters put forward in this edition still show the relative novelty of cultural approaches in DRR with a greater focus on conceptual quandaries (e.g. Hewitt) and evidence from failures in integrating culture and technology (e.g. Geiselhart et al.) than practical suggestions. Nevertheless, as one of the first of its type, this book fairly comprehensively grapples with the major theoretical and practical issues facing researchers in culture and disasters. Both a book with highly usable chapters for students and innovative chapters that further the research agenda, the editors are to be commended for taking on such a challenge and providing the research community with a go-to book for anyone approaching the sticky subject of culture and disasters.

Competing interests

The author declares that she has no competing interests.

Received: 12 December 2015 Accepted: 19 December 2015 Published online: 13 July 2016

\section{Submit your manuscript to a SpringerOpen ${ }^{\circ}$ journal and benefit from:}

- Convenient online submission

- Rigorous peer review

- Immediate publication on acceptance

- Open access: articles freely available online

- High visibility within the field

- Retaining the copyright to your article

Submit your next manuscript at springeropen.com 